\title{
The power of enthusiasm in collaborative innovation: a case study of the power of individual action in the establishment of a local medical centre in Norway
}

\author{
Siv Magnussen \\ Centre for Care Research \\ NTNU, Gjøvik \\ siv.magnussen@ntnu.no
}

\begin{abstract}
The aim of this article is to address a much-neglected aspect of collaborative innovational analysis: the power of individual action in the conversion of innovative ideas to local practice. The theoretical framework for the empirical analysis comes from the existing literature on power, collaborative innovation, and public-sector entrepreneurs. On the basis of an in-depth single-case study, this article highlights how one enthusiastic person can acquire a power base that is strong enough to realize her innovational efforts. Overall, this article emphasizes that collaborative innovation can create opportunities for single individuals who have the will and the energy required to innovate. Moreover, it illustrates that the power of such enthusiastic individuals is an important driving force in innovational processes.
\end{abstract}

Keywords: collaborative innovation, power, public entrepreneurs, enthusiasm, case study, healthcare service

\section{Introduction}

Collaborative innovation is increasingly seen as the way for the public sector to find new and better solutions to complex challenges (Hartley, Sørensen \& Torfing, 2013). However, the sources of collaborative innovation processes are still not well understood (Bommert, 2010). Simultaneously, the subject of power is barely touched upon in the literature and studies on public-service innovation. This absence remains despite the broad acknowledgement that power is 'the basic energy to initiate and to sustain action translating intention into reality (...)' (Bennis \& Nanus, 1985, p. 15). In order to address some of the gaps in this area, the aim of this article is to analyse and discuss the power of individual actors in collaborative innovation. To this end, this article will present the results from a case study of the process of adoption and implementation of a nationally promoted health-service idea in one inter-municipal cooperative region in Norway. This collaborative innovation originates from the Norwegian 
Coordination Reform (Green Paper no. 47 (2008-2009)), launched by the government in 2009. Like many other Western countries, the coordination between healthcare levels is a constant challenge in Norway, as is the fact that healthcare spending per capita has not achieved a correspondingly high level of health in return (Green Paper no. 47 (2008-2009)). As one suitable way of dealing with these challenges, national authorities have encouraged municipalities to cooperate and innovate through the formation of local medical centres (LMC). The term LMC refers to the creation of new healthcare services for patients before, after, and instead of hospitalization. This broad definition allows room for interpretation. Moreover, in order to underline the concept of collaborative innovation, the government has emphasized that establishment of LMCs must be based on local conditions and needs (Prop. 91.L. (2010-2011)). In addition, a major national policy has been to provide short-term economic incentives to municipalities that want to establish local LMCs through intermunicipal cooperation.

The LMC is a case of innovative activity unfolding across organizational boundaries where neither the roles nor the characteristics of those who participate are made clear. Moreover, because innovation means doing something new and different, it will always challenge prevailing and well perceived political and organizational conditions (Windrum \& Koch, 2008). Hence, innovation requires energy from the multiple actors involved (Hartley, 2014). Furthermore, we should not overlook that nationally promoted innovations provide opportunities for people who have the will, interest, and energy required to innovate. The last consideration begs the question: who are those individuals or groups of individuals who have contributed to converting the LMC idea into local praxis?

This case study provides insight into how one nurse without much formal power or authority could stand out as a strong driving force in the conversion of the LMC idea into praxis. In this context, it is interesting to examine how the subject of power relates to the role and behaviour of individual actors in collaborative innovational processes.

Combining theoretical perspectives of power and the role of individual actors, this article provides a new theoretical framework for the understanding of power in collaborative innovation. Overall, the article offers a perspective on the power of enthusiasm as a crucial driving force in collaborative innovational processes.

\section{Collaborative innovation in the public sector}

While the literature on New Public Management (NPM) has emphasized the role of the entrepreneur as a central source of innovation (Sørensen \& Torfing, 2011b), scholars inspired by ideas of New Public Governance have promoted collaboration and multi-actor engagement as a better innovational strategy in public-service organizations (Bommert, 2010). At the core of the concept of collaborative innovation is the idea that governments should adopt a form of innovation where a diverse base of organizations and individuals discover, develop, and implement ideas within and outside organizational boundaries (Bommert, 2010; Borins, 2001; Eggers \& Singh, 2009). This concept further holds that complex problems in the public sector cannot be solved without engagement and involvement from multiple individuals in different roles and positions (Sørensen \& Torfing, 2011b). Thus, collaborative innovation is a process where stakeholders share power in the decision-making in order to make shared and new solutions to complex problems that cannot be solved without multi-actor engagement (Roberts, 2000). In line with current literature 
on public-service innovation (Hartley, 2005; Sørensen \& Torfing, 2011b), innovation in this article includes the 'reinvention or adoption of ideas to a new context, location or time period' (Hartley, 2005, p. 27). This study regards the case investigated as a case of collaborative innovation because different persons on different organizational levels have cooperated to create innovation.

Although collaboration is based on a model of shared power, collaborative innovational processes do not automatically translate into power equality (Gray, 1989). Sources of power and arenas for use of power will always shape the direction and outcomes of innovational processes (Bommert, 2010; Purdy, 2012). Moreover, some individuals or groups of individuals may be more dominant and powerful than others (Gray, 1989; Roberts, 2000; Rønning \& Knutagård, 2015; Young, 2002).

To engage in 'real' collaborative strategies, power has to be dispersed, but not contested (Roberts, 2000). Collaborative skills are still limited, and although multi-actor engagement may in many instances be characterized as a smooth interaction, it is often a conflict-based game (Sundbo \& Fuglsang, 2002). Hence, we should not ignore that innovations appear more often as a result of contested power relations and constellations than as a result of collaborations (Roberts, 2000; Rønning \& Knutagård, 2015).

\section{Power}

One of the most widely used definitions of the concept of power is as follows: $A$ has power over $B$ to the extent that $A$ can get $B$ to do something that $B$ would not otherwise do (Lukes, 2005). This definition is relevant for the current research because it underlines that power is not necessarily connected to formal positions and authority. It also takes individual differences related to one's expertise, information, charisma, and goodwill into consideration (Treadway, Breland, Williams et al., 2013). Nevertheless, it is important to note that the subject of power comprises both policy structures and contextual conditions (Rønning \& Knutagård, 2015). Different political structures, processes and contextual conditions raise different power games. Thus, power is always embedded in socially constructed structures and has to be seen as multi-layered (Arts \&Tatenhove, 2004).

Asymmetries of power in collaborative arenas may prevent certain groups of actors from voicing their opinion and bringing new ideas to the table (Torfing, Sørensen \& Fotel, 2009). Asymmetries of power due to authority may cause such biases. Conversely, authority may also be used to empower actors or groups of actors to participate more effectively in collaboration than others (Purdy, 2012). Thus, a lack of authority does not necessarily mean a lack of power. For example, this is the case if a participant is perceived to advocate a socially important idea (Purdy, 2012).

The most effective way for individuals without formal authority to achieve power is to make others involved dependent on them (Mechanic, 1962). Employees without formal sources of power may achieve considerable informal power owing to their expertise, information, friendly disposition, and as a result of their position within the organization (Mechanic, 1962; Treadway, Breland, Williams et al., 2013). The extent to which lower-ranking participants exercise power depends in part on their willingness to exert effort in areas where higher-ranking participants are often reluctant to participate, and the effort exerted relates directly to the degree of interest one has in an area (Mechanic, 1962, p. 359). 
Some individuals may be more enthusiastic than others. Overall, some people can build a larger power base than others and increase their chances to win and define the problem and solutions in a way they see fit (Roberts, 2000). In this article I define 'power base' as the available resources individuals possess.

\section{The role and power of individual actors}

While studies of collaborative innovation (Hartley, Sørensen \& Torfing, 2013; Sørensen \& Torfing, 2011a) have played down the role of individual actors in favour of multiple action, public-entrepreneurship studies have focused on creative individuals, often termed 'public entrepreneurs', as the primary source of innovation (Osborne \& Brown, 2005; Windrum, 2008). The literature on public entrepreneurs regards the link between personality traits and the entrepreneurial role as essential to innovation (Roberts \& King, 1996; Windrum, 2008). Public entrepreneurs' success at translating ideas into practice is closely linked to their highly creative, self-confident, hard-working, charismatic, decisive, energetic, and dedicated behaviours (Roberts \& King, 1996, p. 11). Through an extensive field study, Roberts and King have developed a model of the public entrepreneur as tenacious and persistent, willing to work long hours and to take risks to reach his goals, and confident and skilled at using political connections (Roberts \& King, 1996, pp. 10-11). With this set of core personality traits, public entrepreneurs are quite often seen as heroes who support and promote innovation against entrenched interests and the status quo in organizations (Osborne \& Brown, 2005). They appear to be change agents who constantly search for ways to convert their visions into reality (Roberts \& King, 1996, p. 145).

Røvik (2007) claims that actors' ability to convert ideas into reality is an area that generally is overlooked and neglected. On the basis of this lacuna, he presents a model of the 'capable translator' as an actor who has detailed knowledge about the idea which should be translated, the context the idea is taken from, and the context into which the idea is going to be translated. The 'capable translator' has to be strong and determined because the translation of ideas often takes place in a context of interest-based power games, negotiations, and conflicts, and where the translator's new local models mobilize resistance as well as support. This requires translators to be able to handle resistance and to understand dimensions of conflict and interests (Røvik, 2007).

Network connections are essential for creative individuals' ability to succeed (Røvik, 2007; Windrum, 2008), and, according to Meijer (2013), 'instead of one hero', distributed heroism is needed for successful innovation (Meijer, 2013, p. 6 ). One hero may be crucial in one part of the process, but may run into problems in another part, for instance, because his role as an 'idea fighter' may be too prominent (Meijer, 2013). This, however, does not mean that individual personality traits and skills are not important drivers in innovational processes (Meijer, 2013; Osborne, 2005). We should keep in mind that such individuals or groups of individuals may increase their chances of obtaining a power base needed to realize their interventions.

A combination of the literature on characteristics of public entrepreneurs and theories of power single out the role of individual actors in collaborative innovational processes. With the empirical data, I shall investigate to what extent personality traits can lead to a power base with implications for using collaborative strategies in public innovation. 


\section{Introduction to the case}

The case in this study involves a region located in a rural part of Norway that comprises six small municipalities. These municipalities, like many others in Norway, struggle to meet the legal requirements and to produce services efficiently. They also have concerns related to depopulation, long geographic distances to the hospital, and a lack of competences and resources to be able to handle future health challenges. Given these circumstances, and because of organizational and economic incentives established by the Coordination Reform, inter-municipal collaboration is seen as an appropriate solution to their challenges. Simultaneously, and consistent with the long-standing tradition of local autonomy in Norway (Andersen \& Pierre, 2010), each of these municipalities wants to retain as many healthcare services as possible in their own municipality. Hence, reaching agreements about new collocated municipal health services has been difficult, and scepticism, resistance and conflict has marked the LMC process.

Since 2002, the region has operated a District Medical Centre (DMC) providing specialist health services in partnership with the local hospital. The DMC was located in the region's biggest municipality. Thus, in contrast to many other LMC cases, this region already had an integrated health centre with similarities to the LMC idea that was presented in national reform documents.

Notwithstanding, the provision of healthcare services in the sense of small medical institutions on a level between primary care and general hospitals is in itself not a new idea. In Norway (Pedersen, 2013) as well as abroad (Tucker, 2006), it has been a widely used concept since the early 1900s. In Norway, such centres have been quite common in rural areas because of long distances to the local hospital. Most of them were called 'cottage hospitals' $(\mathrm{CH})$ or District Medical Centres (DMC). After 1970, the Norwegian government prioritized the development of general hospitals, and the number of CHs or DMCs declined (Aaraas, 1998). In the wake of the Coordination Reform (Green Paper no. 47 (2008-2009)), national authorities have brushed the dust off this idea and changed the term $\mathrm{CH}$ or DMC to LMC. Such centres are said to be desirable, both in rural areas and in cities, to handle new municipal responsibilities in the wake of the reform.

We may regard December 2008 as the starting point for the new plans for the region's already established DMC that at that time lacked physical space. Simultaneously, the nursing home in the biggest municipality was 'out of date'. Furthermore, the newly launched Coordination Reform stressed innovation through inter-municipal cooperation. To address these issues, some of the leaders in the region's largest municipality and the nurse who is the focus of the study suggested establishing a new LMC comprising a new nursing-home unit, an intermediate unit, and the already existing DMC. A few months later, the nurse and these leaders applied for and obtained short-term economic incentives from the state, a move that had political backing in all six municipalities. The aim was to identify interest in the establishment of new collaborative healthcare services in the region, and whether the new LMC was needed and possible to establish.

The nurse who at that time worked as a health advisor in the biggest municipality was very enthusiastic about the establishment of a new LMC. Because of her strong engagement, she was appointed as project coordinator for the LMC project. This position did not entail authority to make any decisions, but through the role as project coordinator, she got the opportunity to be a driver in the 
innovational process. Today, the region's new LMC has been established in accordance with how it was presented for the first time in 2008.

\section{Research design and method}

We can view the presented case as informative. I have selected it partly because it has many similarities to other LMC processes in the wake of the Norwegian Coordination Reform, and partly because it is different, as it already had a DMC (Magnussen \& Tingvold, 2015). The benefits of a single-case study lies both in its capacity to investigate a phenomenon in depth in its real-life context and in the investigator's opportunity to use a variety of data-collection methods (Flyvbjerg, 2006; Gerring, 2004, 2007). The strength of this case study is that it enabled me to follow the process from the birth of the idea to the establishment of the new LMC. The data material included interviews and participant observation, which have strengthened the internal validity of the case.

\section{The interviews}

The selection of informants resembles snowball sampling (Atkinson \& Flint, 2001), starting with an inquiry to the nurse and one of her managers. I then undertook semi-structured interviews with 12 key actors involved in the establishment of the new LMC. Common for all the informants was their participation in this innovational process. Table 1 specifies the informants' roles and relation to the LMC project. The duration of the interviews was from one hour to one hour and a half. All except one of the informants had lived and worked in the region for many years. They were interviewed about their experience of how the development of the LMC took place in their region. I interviewed the project coordinator twice with approximately a two-year interval between interviews $(2010,2011)$. The other interviews were conducted in autumn 2011 and in spring 2012.

Table 1: List of informants

Informant Profession/Role Relation to the LMC

\begin{tabular}{|c|c|c|}
\hline 1 & Nurse in leadership position & Member of the project group \\
\hline 2 & Municipal Administrator & Member of the project group \\
\hline 3 & Municipal Administrator & Familiar with the LMC plan \\
\hline 4 & Nurse in leadership position & Member of the project group \\
\hline 5 & Physician & $\begin{array}{l}\text { Initiator and member of the project } \\
\text { group }\end{array}$ \\
\hline 6 & Project adviser & Member of the project group \\
\hline 7 & $\begin{array}{l}\text { Nurse, health adviser in the } \\
\text { biggest municipality }\end{array}$ & $\begin{array}{l}\text { Initiator and project coordinator of } \\
\text { the project group }\end{array}$ \\
\hline 8 & Politician & Strongly involved in the process \\
\hline 9 & Politician & Strongly involved in the process \\
\hline 10 & Nurse in leadership position & Member of the project group \\
\hline 11 & Nurse in leadership position & Member of the project group \\
\hline 12 & Physician & Familiar with the LMC plan \\
\hline
\end{tabular}




\section{The observational period}

The participant observation took place between 2009 and 2014 and consisted of participation in a broad variety of meetings, seminars, and workshops connected to the planning process of the LMC. During the period of observation, I had regular contact with the project coordinator by telephone, e-mail, and in person before and after the meetings. I also participated in a study tour arranged by the LMC project group. I had access to the case region's project reports, PowerPoint presentations, and minutes from their meetings. Participant observation and access to all of the project's written documentation provided an opportunity to get first-hand insights into how the actors involved discussed and planned their LMC, including insights into various issues affecting the individual municipalities' LMC processes.

\section{Data collection and analysis}

The data from observations were collected through hand-written field notes. I developed and adapted the initial semi-structured interview guide as new questions emerged. The main focus was nonetheless the collaborative process of the establishment of the LMC. All the interviews were recorded on tape and then transcribed.

I read and analysed the field notes from the observations and written documents, listened to and transcribed all the recorded interviews. All the interview data and parts of the observation notes and written documents were coded and categorized with the qualitative analysis programme NVivo. I began with 'open' coding (Glaser \& Strauss, 1967). The purpose of the open-coding process was to generate codes directly from the data (Strauss \& Corbin, 2014). Most of the data-generated codes were labelled from words found in the data itself. Subsequently, I categorized the codes in terms related to the research question: 'Who contributes to converting the LMC idea into local praxis?' In this part of the analysis I found an interesting link between power and individual actors' enthusiastic engagement in the innovational process. Accordingly, I focused on the development of theory and how present theory could contribute to the understanding of my empirical data. Through this interactive inductivedeductive approach the aim was to get a sharp and in-depth understanding of the innovational process in establishing the new LMC.

\section{Case analysis}

The case analysis includes the two phases where the establishment of the LMC project was assessed and decided politically. In the first phase the project group's mission was to investigate the need for a new regional LMC. In the second phase they planned the content, localization and organization of a new LMC. By following these two phases closely, I received insight into the scepticism, conflicts, and resistance regarding the LMC. Furthermore, I became aware that the project coordinator, owing to her enthusiasm for the LMC project, played a central role in putting it on the local political agenda and in steering the content and structure of meetings and other activities related to the LMC. The further analysis will elaborate on these aspects, including the nurse's strategies to succeed in establishing the LMC.

\section{Scepticism, conflicts, and resistance}

Especially in the first phase of the project, the nurse hired as a project coordinator felt that leaders, politicians, and physicians in some of the 
participating municipalities frequently opposed her. She also stated that she had been disappointed by the lack of involvement and support from people she had expected would understand the importance of a new LMC. Despite these negative experiences, she said, 'I am an optimist; with more constructive information, I think we will succeed'.

Other informants also described the first phase of the LMC process as marked by scepticism, resistance, and conflict. One of the physicians actively involved in the process said:

We have a 'Physicians' Club', a forum where all the physicians in the region meet several times a year. The atmosphere usually tends to be very good and we agree on most things. I would say that this [the LMC idea] is the case where we have had the most disputes and conflicts in the almost 30 years l've been here. (5)

Some claimed that the LMC could result in health services with lower quality and safety. Another contested subject was the location of the LMC. All of the municipalities involved had long and strong traditions of local political autonomy, and many stakeholders (politicians, leaders, physicians, and other health professionals) still wanted to keep most of their healthcare facilities in their own municipality. Thus, a concern that was often voiced was a lack of jobs and competences in each of the municipalities when the focus was on the regional level. The most prominent concern was related to the lack of financial resources. Some assumed that the establishment of the LMC would be at the expense of the ordinary primary healthcare services in each of the municipalities. Because of the location, some also asserted that they were not interested in paying for the biggest municipality's new nursing-home unit.

Instead of attempting to resolve scepticism and conflicts through collaborative effort and through learning from one another, the strongest opponents remained on the sidelines and discussed the idea in negative terms. Regarding some of the physicians' attitude, an informant said:

Some physicians have renounced intermediated care services. They call it not very nice things! They say they are never going to refer patients there. They do not attend venues where the LMC idea is presented and discussed, except perhaps occasionally in the Physicians' Club, to announce their opposition. (2)

The physicians' resistance was not just observed in this study, but has been debated since the idea of intermediated healthcare and emergency health services was launched by the Coordination Reform (Skinner, 2015). However, other opponents, particularly politicians and people in leadership positions in the surrounding municipalities, showed resistance with their absence from collaborative meeting places. One informant explained the use of such soft resistance as follows:

In the beginning, the LMC idea was more like a castle in the air. I think many of the opponents thought this idea would just blow away or die if they didn't engage in it. (10)

However, despite widespread scepticism, conflicts, and resistance expressed through absence, negative talk, and threats about not referring patients to the suggested intermediated unit, the LMC idea did not die out. 


\section{The nurse's enthusiasm for the LMC idea}

The nurse was quite convinced that a new LMC was the best way to address new responsibilities referred to in the Coordination Reform (Green Paper no. 47 (2008-2009)). Thus, through her role as project coordinator and by virtue of her professional knowledge and experience from primary healthcare, she talked about the LMC idea with exceptional energy. As one administrative leader said:

There is no doubt where the professional enthusiasm and zeal is located (...). It is pretty clear that this enthusiasm has been a major driving force in the project. (3)

The nurse's strongest argument for a new LMC was that shorter travelling distances to specialist services and access to treatment in a safe and familiar environment would provide better and more cost-effective healthcare services. Because of her professional eagerness to establish the new LMC, she also stood out as an energetic and dedicated project coordinator, with a deep commitment and drive to convince people in her environment that the establishment of the LMC was the only right thing to do.

Her personality traits had many similarities with Roberts and King's (1996) characteristics of the public entrepreneur. She had the self-confidence needed to handle resistance. From her point of view, resistance was a natural part of the process, caused by a lack of information and knowledge about the upcoming tasks described in the Coordination Reform. As she put it:

I think it [resistance] is because of some strong actors who don't understand the consequences of 'not being in', and because of some politicians who don't have enough competence to see the consequences, and thus do not appear to be sufficiently convincing. Hence, I think more information is the key to handle this. (7)

Furthermore, as the next quotation illustrates, she was tenacious and not afraid of taking risks:

I think a new LMC will provide economic challenges for the involved municipalities, but it might also lead to something positive, for instance, because it leads us to think and handle primary health services in a different and new way. (7)

From the observational data, it was clear that the nurse was confident and skilled in using political connections too. She invited politicians and professional experts to speak about the benefits of the LMC concept at regional venues. If something was unclear or problematic, she did not hesitate to make a phone call to national political authorities. She was not afraid of working long hours either. She searched continually for information and knowledge that could strengthen the reasons why the region should implement the innovation. In the second phase of the project, her job was estimated to be full-time employment for four months. In the written report from this period, her real workload ended up being full-time work for six months. Overall, she worked significantly more than her position warranted.

\section{The power of individual action in collaborative innovation}

The empirical analysis indicates that the nurse, with the entrepreneurial skills described above, developed four key strategies, which were either intentional 
or unintentional: 1) a monopoly of expertise knowledge; 2) strength and determination; 3) enthusiasm, bravery, and an orientation to the future; and 4) connections and alliances. In sum, her use of these strategies provided her with an opportunity to bring the LMC idea forward. First, through political connections and hard work, she became an expert on the LMC idea, the context the idea was taken from, and the regional context. She actively used her expert knowledge and information in her presentations, and she stressed that the LMC idea aligned fully with national political guidelines. Owing to this expert knowledge monopoly, she received the responsibility to obtain, maintain, and control the conversion of the LMC idea.

The nurse's second strategy relates to the virtues of strength and determination. From the very beginning, the nurse appeared as a strong, positive, and resultoriented front figure. Owing to her perception of other stakeholders' resistance as the result of a lack of information and knowledge, she maintained her belief in the LMC idea. Furthermore, with considerable determination, she consistently strengthened the process of conversion of the LMC idea. For instance, one informant said that people in the regional nurse's organization had in the beginning expressed scepticism to the idea, but to quote this nurse:

In a meeting, the project leader preached about the LMC project for two hours. You know how she is! Afterwards we had a discussion and the scepticism disappeared. (4)

Not only does this quotation show the nurse's determination, it also illustrates how her energetic and charismatic traits, and not least, her professional selfconfidence, diminished scepticism and resistance.

The nurse expressed her own reflections about her role as follows:

Politicians have requested my expert knowledge on many occasions. They have experienced that I have been able to answer their questions. I've been working on this for many years so I think I know a lot about the Coordination Reform - and that, I think, politicians have confidence in. When I come to inform them about things, I talk about things I know! It is not something I believe, but something I've learned. I think I have provided security for politicians (...) but - so, I may [also] become a threat because I'm so convinced this is something we must do in the region. (7)

In the beginning of the LMC project, the nurse also hired an 'inspirational agent' to speak about how to succeed with innovations, using enthusiasm as a prime strategy. The agent made a strong impression. During the first phase, the official vision of the LMC project became 'bravery, enthusiasm, and future orientation'. This vision also turned out to be important in the second phase and may be seen as the third strategy, used to combat resistance. As one of her supporters in the host municipality put it:

The surrounding municipalities are not very easy to handle. On the one hand, it is expected that we pull the load, and so we largely do. On the other hand, we are criticized because we decide too much and are locating everything in our municipality. (...) We have used the vision and value foundation for all its worth to remind us that we have agreed that generosity, bravery, and enthusiasm are important factors in our LMC project. (2) 
This quotation shows that the vision of enthusiasm and braveness was used as a strategy. It also shows that the nurse was not the only one fighting for a new LMC. From the very beginning, she had close connections to leaders with more authority than herself. In her own description of the process, she emphasized that the medical leader for the already established DMC and some of the leaders in the host municipality were valuable allies:

The head of the DMC and the leaders in the host municipality have been adept at providing information in their forums - If something was unclear, they stepped in very quickly and took of it by themselves, or they dragged me into it right away. (7)

The quotation shows the nurse's ability to mobilize support and trust, which enabled her to participate more effectively than others.

As a further illustration of how powerful actors trusted and supported the nurse's suggested LMC plan, the following statement from one informant in a leadership position may serve as an example:

This research work is on a very high level, and I know what good research work should consist of. (3)

This quotation can be seen as an example of how a leader used his authority to strengthen the LMC plan. Simultaneously it also illustrates how powerful actors can use their authority to empower individuals or groups of individuals to speak in favour of an important issue (Purdy, 2012). Hence, because of the nurse's interaction with these leaders, her fourth strategy can be described as her willingness and capacity to make connections and alliances with people with more authority than herself.

Overall this analysis shows how the nurse stood out as an energetic and enthusiastic person with a deep commitment and drive who won over scepticism, conflicts, and resistance. In other words, her development of the four strategies described above seemed to produce a power base strong enough to overcome the resistance expressed by the opponents.

\section{Closing discussion}

This in-depth case study illustrates how a very enthusiastic and dedicated nurse played an important role in the conversion of the national LMC idea to local praxis. Physicians, leaders, and politicians with differing views on what was the 'right' thing to do had the power to contest the LMC process. However, they contested the suggested LMC only to a very limited degree. One explanation may be that the national political support for the LMC innovation made it difficult for local authorities to express their resistance loudly. It is possible that physicians and politicians, owing to their formal positions, thought that the whole idea would disappear if they did not engage in the process. If one thinks of power in the form of a bureaucratic silo structure and hierarchical, top-down processes (Bommert, 2010), this might have happened, but it did not. Instead, these powerful opponents' absence and soft resistance seem to have enhanced the nurse and her supporters' ability to succeed with their LMC plan. Hence, while other studies (Windrum \& Koch, 2008) have revealed the public sector's need for champions to succeed with innovations, a key finding in this study is how collaborative innovation creates space for single individuals who have the will and energy required to innovate. 
The findings regarding the relationship between power and personality traits show how the nurse, either intentionally or unintentionally, developed four strategies that seemed to make it difficult for both opponents and more neutral stakeholders to contradict the realization of the LMC idea during the process.

The nurse's strategies of expertise knowledge monopoly and strength and determination overlap with Røvik's (2007) description of the 'capable translator'. In line with Røvik's proposals, the analysis shows how the nurse's strong and determined attitude, combined with a will, interest, and energy to acquire as much knowledge as possible, were crucial for her capacity to handle resistance and to make others feel confident about the LMC. When the local political authorities made their overall decision regarding the LMC idea, they trusted the nurse's suggestions.

The nurse's third strategy is closely connected to her energetic and optimistic personality, as well as her willingness to take risks. From the very beginning, she was quite convinced that a new LMC, despite its huge economic costs, was the best way to handle the new and expanded health responsibilities signalized in the Coordination Reform. Enthusiasm, bravery, and future orientation also became the official vision of the LMC plan, and was used as trump card in disagreements during the process.

Nevertheless, in line with other public entrepreneurial studies (Meijer, 2013; Windrum, 2008), this case study highlights that no single individual can carry out innovations by themselves but needs to build meaningful connections with others. Therefore, the nurse's fourth strategy related to her skills to maintain and develop new connections and alliances with people who had more authority than herself. One example of these connections was the medical leader at the already established DMC; another was her alliances with some of the leaders in the host municipality. Although none of these stood out as strong advocates for the new LMC, it was no secret that they supported the professional justifications of the LMC idea. Thus, like Meijer's (2013, p. 14) concept of heroes as idea fighters, this nurse's behaviour and skills may be seen as a valuable innovational force for positive leaders more bound by organizational routines and lacking the time to fight for innovation (e.g., the medical leader at the DMC).

This article does not claim that complex problems in the health sector can be solved by enthusiasm or by single individuals. However, it underscores that individual actors without much authority can obtain a power base strong enough to steer the direction and outcomes in collaborative innovational processes through enthusiasm and entrepreneurial traits

How individuals acquire power has been less prevalent in the literature (Treadway, Breland, Williams et al., 2013), and so a key finding of this study is the effect of nurse's self-confident and persuasive attitude (Roberts \& King, 1996; Windrum, 2008). Owing to her enthusiastic and determined attitude, the data indicates that she behaved if she had the power to realize her own and her supporters' innovational efforts. As she often said, 'I talk about things I know! It is not something I believe, but something I've learned'. Although such an attitude does not harmonize with a collaborative-innovation ideology (Sørensen \& Torfing, 2011a), it is appropriate to quote Meijer, who says, 'that a process of innovation seems to require a rebel in the early phase of the innovation process to challenge organizational routines' (Meijer, 2013, p. 14). Hence, it should not be overlooked that the power of enthusiastic and convincing heroes, in this case a heroine, is necessary to achieve innovations. 
This study illustrates how people who have the energy required to innovate can take the opportunity that ideas of collaborative innovation provide to take a driving seat in the process. The unclear outcomes resulted from the development of the LMC unfolding across organizational boundaries, where neither the roles nor the characteristics of those who participated were made clear. It contributes to the understanding of how unresolved collaborative relationships encompass an opportunity for enthusiastic individuals to produce a power base strong enough to overcome resistance and to steer the direction in innovational processes. This, however, does not mean that such energetic behaviour is enough to realize successful collaborative innovations, as the power of individual action in one part of the process may be a problem in another (Meijer, 2013). In the phases of innovation conducted in this study, the nurse's conviction about her own perspectives as the right ones can be seen as necessary, and a reason for success. Simultaneously, in the next steps it may entail challenges because such an attitude can make it more difficult to be open to other perspectives and to accept necessary compromises. Thus, in order to bring an innovation to success, there is a need for different types of heroes in the different phases of the process (Meijer, 2013).

Because innovational processes have their own dynamics and are influenced by the specific organizational and institutional settings (Meijer, 2013), this case study cannot be generalized to other processes of innovation. Nevertheless, this specific case has revealed that more attention has to be paid to the power of enthusiastic individuals in collaborative-innovation studies.

\section{Acknowledgements}

My thanks to Professor Rolf Rønning, Professor Albert Meijer, and Associate Professor Laila Tingvold for constructive comments in the writing process. I would also like to thank editor and reviewers in NJSR for your very carefully review of my paper.

\section{References}

Aaraas, I. (1998). General practitioner hospitals : use and usefulness : a study from Finnmark County in North Norway. (Doctoral thesis), UiT The Arctic University of Norway, Tromsø.

Arts, B. \& Van Tatenhove, J. (2004). Policy and power: A conceptual framework between the 'old' and 'new' policy idioms. Policy sciences, 37(3-4), 339-356.

Andersen, O. J. \& Pierre, J. (2010). Exploring the strategic region: Rationality, context, and institutional collective action. Urban Affairs Review. 46(2), 218-240.

Atkinson, R \& Flint, J. (2001). Accessing Hidden and Hard-to-Reach Populations: Snowball Research Srategies. Social research update, 33(1), 1-4.

Bennis, W. G., \& Nanus, B. (1985). Leaders. The strategies for taking charge. New York: Harper \& Row.

Bommert, B. (2010). Collaborative innovation in the public sector. International public management review, 11(1), 15-33.

Borins, S. (2001). The challenge of innovating in government. Arlington: Pricewaterhouse Coopers Endowment for the Business of Government

Eggers, W. D \& Singh, S. K. (2009). The Public Innovator's Playbook: Nurturing Bold Ideas in Government: Harvard Kennedy School ASH Institute for Democratic Governance and Innovation. 
Flyvbjerg, B. (2006). Five Misunderstandings About Case-Study Research. Qualitative Inquiry, 12(2), 219-245.

Gerring, J. (2004). What Is a Case Study and What Is It Good for? American Political Science Review, 98(2), 341-354.

Gerring, J. (2007). Case study research : principles and practices. Cambridge: Cambridge University Press.

Glaser, B. \& Strauss, A. (1967). The Discovery of Grounded Theory: Strategies for Qualitative Research. Chicago: Aldine Publishing.

Gray, B. (1989). Collaborating: Finding Common Ground for Multiparty Problems. San Francisco: Jossey-Bass Publishers.

Green Paper no. 47 (2008-2009). Norwegian Ministry of Health and Care Services (2008-2009). The Coordination Reform. Proper treatment - at the right place and right time. Summary in English: Report no. 47 (2008-2009) to the Storting. Oslo: Norwegian Ministry of Health and Care Services.

Hartley, J. (2005). Innovation in governance and public services: Past and present. Public money and management, 25(1), 27-34.

Hartley, J. (2014). New development: Eight and a half propositions to stimulate frugal innovation. Public Money \& Management, 34(3), 227-232.

Hartley, J., Sørensen, E. \& Torfing, J. (2013). Collaborative Innovation: A viable Alternative to Marked Competitition and Organizational Entrepreneurship. Public Administration Review, 73(6), 821-830.

Lukes, S. (2005). Power: A Radical view. New York: Palgrave.

Magnussen, S. \& Tingvold, L. (2015). Utvikling av lokalmedisinske sentra (LMS) som interkommunal idéhåndteringsprosess (Development of the local medica centre as national idea and intermunicipal management process). Nordiske Organisasjonsstudier (The Nordic Journal of Organisation Studies), 17(1), 6283.

Mechanic, D. (1962). Sources of Power of Lower Participants in Complex Organizations. Administrative science quarterly, 7(3), 349-364.

Meijer, A. J. (2013). From Hero-Innovators to Distributed Heroism: An in-depth analysis of the role of individuals in public sector innovation. Public Management Review, 16(2), 199-216

Osborne, S. P. \& Brown, K. (2005). Managing Change and Innovation in Public Service Organizations. New York: Routledge.

Pedersen, T. H. (2013). Senterideen i samhandlingsreformen: Hjemlige og internasjonale inspirasjonskilder [The Center Idea in the Coordination Reform: Domestic and international inspirations]. In N. Veggeland (Ed.), Reformer norsk helsevesen [Reforms in the Norwegian Health Sector] (pp. 199-224). Trondheim: Akademika forlag.

Prop. 91.L. (2010-2011). Lov om kommunale helse- og omsorgstjeneste [Law on health and long-term care].

Purdy, J. M. (2012). A Framework for Assessing Power in Collaborative Governance Processes. Public Administration Review, 72(3), 409-417.

Roberts, N. C. (2000). Wicked problems and network approaches to resolution. International public management review, 1(1), 1-19.

Roberts, N. C. \& King, P. J. (1996). Transforming Public Policy. Dynamics of Policy Entrepreneurship and Innovation. San Francisco: Jossey-Bass Publishers.

Rønning, R. \& Knutagård, M. (2015). Public Innovation. A question of power? In R. Rønning \& M. Knutagård (Eds.), Innovation in Social Welfare and Human Services (Chapter 5). London: Routledge. 
Røvik, K. A. (2007). Trender og translasjoner. Ideer som former det 21. århundrets organisasjon. [Trends and translations. Ideas that shape the 21st century organizations]. Oslo: Universitetsforlaget.

Skinner, M. S. (2015). Skeptiske leger og tomme senger? Bruken av de kommunale akutte døgnplassene [Skeptical doctors and empty beds? The use of the municipal acute beds]. Senter for omsorgsforsknings rapportserie nr. 10 [Center for care research, report nr. 10] Gjøvik, Norway: Høgskolen i Gjøvik.

Strauss, A. L. \& Corbin, J. M. (2014). Basics of Qualitative Research. Techniques and Procedures for Developing Grounded Theory. Thousand Oaks, California: Sage Publications.

Sundbo, J. \& Fuglsang, L. (2002). Innovation as strategic reflexivity. Routledge Advances in Management and Business Studies, 22, 1-16.

Sørensen, E. \& Torfing, J. (2011a). Enhancing collaborative innovation in the public sector. Administration \& Society, 43(842), 842-868.

Sørensen, E. \& Torfing, J. (2011b). Enhancing Collaborative Innovation in the Public Sector. Administration \& Society, 43(8), 842-868.

Torfing, J., Sørensen, E. \& Fotel, T. (2009). Democratic anchorage of infrastructural governance networks: The case of the Femern Belt Forum. Planning Theory, 8(3), 282-308.

Treadway, D. C., Breland, J. W., Williams, L. M. et al. (2013). Social Influence and Interpersonal Power in Organizations Roles of Performance and Political Skil in Two Studies. Journal of Management, 39(6), 1529-1553.

Tucker, H. (2006). Integrating Care in Community Hospitals. Journal of Integrated Care, 14(6), 3-10.

Windrum, P. (2008). Innovation and entrepreneurship in public services. In P. Windrum \& P. Koch (Eds.), Innovation in Public Sector Services: Entrepreneurship, Creativity and Management (pp. 3-20). Cheltenham: Edward Elgar Publishing.

Windrum, P. \& Koch, P. (2008). Innovation in Public Sector Services. Cheltenham: Edward Elgar Publishing

Young, I. M. (2002). Inclusion and Democracy. New York: Oxford University Press 